\title{
SYDENHAM CHOREA WITH DIFFICULTY TO CONTROL: CASE REPORT
}

Simone Soares Lima ${ }^{1}$, Catarina Fernandes Pires ${ }^{1, \star}$, Ana Teresa Spíndola Madeira Campos ${ }^{1}$, Ana Karoline Batista Burlamaqui Melo ${ }^{1}$, Liana Soido Teixeira e Silva ${ }^{1}$, Roberta Oriana Assunção Sousa da Ponte Lopes², Leiva de Souza Moura², Raissa Lua Rodrigues Araújo de Carvalho², Diego Mesquita Cascimiro ${ }^{1}$, Mariana Moura Diniz Araújo ${ }^{1}$, Fernando Nascimento de Carvalho Filho ${ }^{1}$, Angélica Maria Assunção da Ponte Lopes ${ }^{1}$, Antonio Allan Camilo Oliveira Silva Sales ${ }^{1}$, Thájara Fernandes de Sá Guimarães ${ }^{1}$, Conceição de Maria Costa ${ }^{1}$, Lúcio Fernandes Pires ${ }^{1}$, Stella Rúbia Lima Araújo de Castro ${ }^{1}$, Tatiane Nayane Pedrosa da Silva ${ }^{1}$, Valério Chaves Pinto Junior ${ }^{1}$, Ana Carla Moreira Paiva ${ }^{1}$, Letícia Oliveira Pereira ${ }^{1}$, Franciele Machado ${ }^{1}$, Ykaro Ysmael Araújo Carneiro Viana ${ }^{1}$, Felipe Araújo Oliveira Dantas ${ }^{1}$, Rayssa Brenda da Silva Lima ${ }^{1}$, Anália Fernandes Pires ${ }^{3}$, Carlos Henrique da Silva Franco ${ }^{4}$

1.Universidade Federal do Piauí, Teresina (PI), Brazil; 2.Hospital Infantil Lucidio Portella, Teresina (PI), Brazil; 3.Centro Integrado de Saúde Lineu Araújo, Teresina (PI), Brazil; 4.Universidade Estadual do Piauí, Teresina (PI), Brazil.

*Corresponding author: fernandespires1@yahoo.com.br

\section{BACKGROUND}

Sydenham chorea (SC), also known as St. Vitus dance, is a manifestation of inflammatory involvement of the basal ganglia and caudate nucleus of the central nervous system, due to acute rheumatic fever. The latency period between the inciting streptococcal pharyngitis and the onset of clinical signs of chorea is longer than that of the other major manifestations of the disease, averaging two to four months, and sometimes extending to as long as 12 months. It is more common in childhood, female, less frequent after 15 years and exceptional after 20 years.
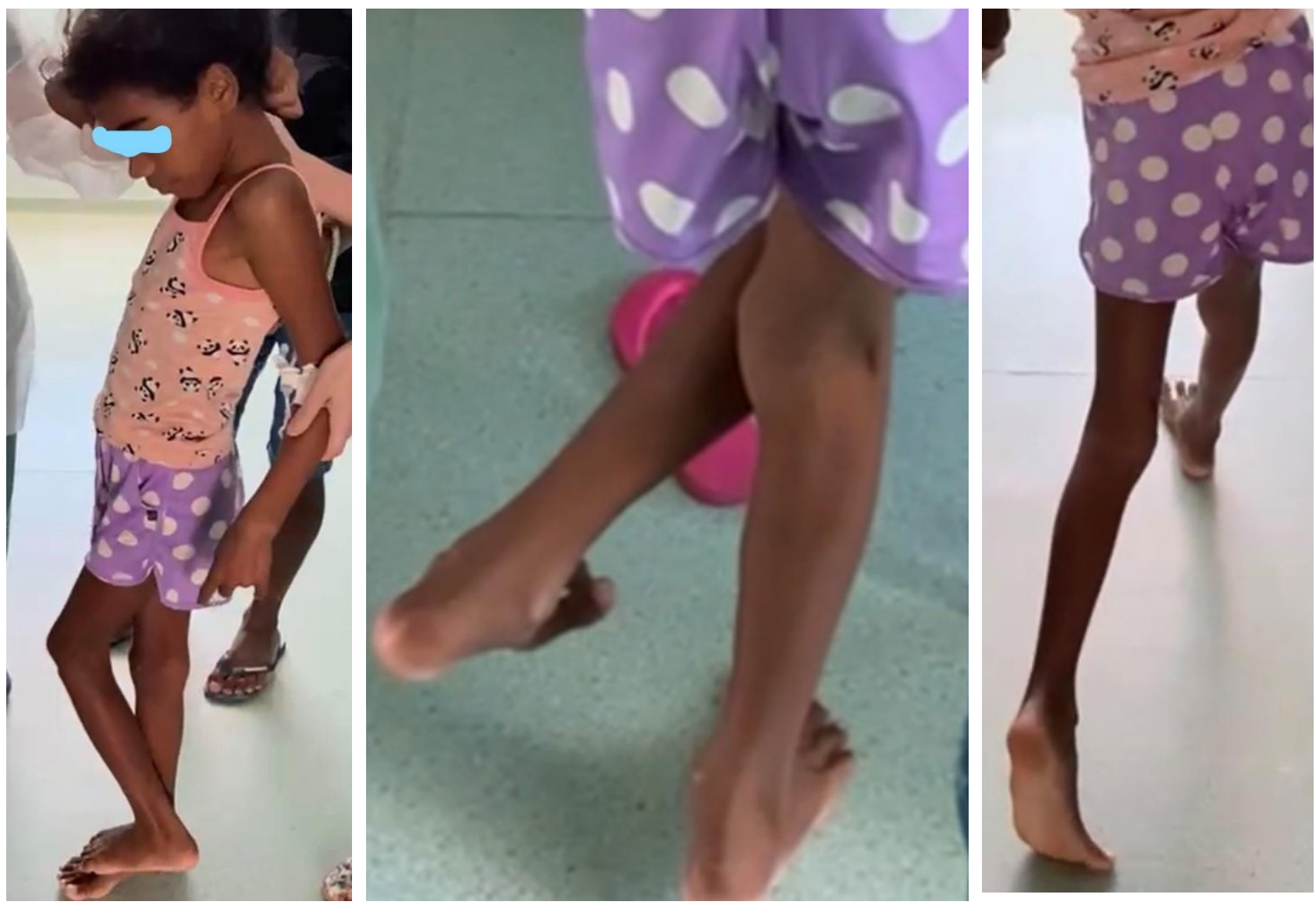

Figure 1. Involuntary and uncoordinated movements in trunk and extending to the extremities of upper and lower limbs.

Realização: 


\section{CASE REPORT}

Adolescent, 10 years old, started 18 days ago, pelvic pain associated with fever and malaise. She was diagnosed with renal and bladder lithiasis associated with urinary infection. Underwent treatment with antibiotics obtaining satisfactory results. Discharged for outpatient monitoring. It presented, from then on, involuntary and uncoordinated movements initiated in the face trunk and extending to the extremities of upper and lower limbs, exacerbated and abrupt when subjected to observation (Figures 1). She also had lability of humor and face movements on a face similar to grimaces and persistent restlessness. Speech was hesitant with voice timbre compromised. Muscle tone decreased. Readmitted for investigation. Complementary exams showed: leukogram 6600; PCR 6 mg/dL; ESR 64 mm/1 sth; ASO $400 \mathrm{lU} / \mathrm{mL}$; lactic dehydrogenase $656 \mathrm{IU} / \mathrm{L}$; rheumatoid factor negative; echocardiography aortic insufficiency discrete. Normal cranial magnetic resonance. Normal electroencephalogram; non-reactive ANA; antibodies not reactive. Negative direct Coombs. Negative cyto-biochemical liquor. Negative serologies for TORCH'S, hepatitis, HIV, chickenpox, Epstein-Barr. Normal coagulogram, normal urine summary. Considering the diagnosis of rheumatic chorea, therapy with penicillin benzathine, haloperidol and promethazine was started; however, no clinical improvement was observed, the pediatric neurologist decided to introduce diazepam and prednisone, noticing improvement, but still slight, then, risperidone was associated and haloperidol and promethazine suspended, with a favorable evolution of the condition.

\section{CONCLUSION}

Sydenham chorea should always be considered in the differential diagnosis of neurological manifestations that progress with involuntary and uncoordinated movements. Research careful diagnosis and early treatment with well-established and can modify the course and prognosis of the disease.

\section{KEYWORDS}

Sydenham chorea, Involuntary and uncoordinated movements, Lability of humor. 